\title{
Teaching Methods based on Futures Studies Development in Iran Higher Education
} Curriculum

\author{
Mehdi Keshavarzi ${ }^{1}$, Mohammad Hossein Yarmohammadian ${ }^{2 *}$, Mohammad Ali Nadi $^{3}$ \\ 1. Ph.D. Student, Department of Educational Science, Isfahan (Khorasgan) Branch, Islamic Azad University, \\ Isfahan, Iran. \\ 2. Professor, Health Management and Economics Research Centre, Isfahan University of Medical Sciences, \\ Isfahan, Iran.*Corresponding author: mhyarm@yahoo.com \\ 3. Associate Professor, Department of Educational Sciences, Isfahan (Khorasgan) Branch, Islamic Azad University, \\ Isfahan, Iran
}

\begin{abstract}
One of the tasks of a university is student's competencies in different areas, including recognition of the future or futures studies. The growth of Students through improved education during the academic years will be able to futures studies; therefore, it can be argued that one of the critical variables that can affect students' futures growth potential, is the quality of their teaching and learning methods. This study aim is to design teaching methods based on the development of futures studies in higher education which was conducted by using grounded theory by the qualitative research. In this study, 12 experts of curriculum areas and futures studies were interviewed. The full text of responses of interviewees was performed from a recorded version in the coding process, the given comments were divided by software MAXQDA 12 into separate concepts and then familiar concepts set in a separate category, and the component of teaching methods was identified as the major categories of research. In the final model, the barriers, strategies, and consequences had presented for compiling of the teaching methods based on the futures studies development separately and in the framework of the analysis models.
\end{abstract}

Keywords: Curriculum, futures studies, teaching methods, higher education.

\section{Introduction}

The effectiveness of the educational system with the development of researches of every country includes the index of measures of developing. With the fact that the new century faces with the rapid changes in various areas enormous, the educational systems of each country, including the higher education system, for the realization of worthy goals must also be able to identify these evolutions and planning for dealing with them. Students also equipped with the knowledge and skills that enable them to identify trends and future issues and be prepared for it; because the first and most important task of the educational system is preparing the students for the needs, challenges and demands of the future (Sardar, 2010). So, one of the functions of universities is student's competencies in different areas, including recognition of the future or futures studies (Masini, 2011). The Origin of the Futures studies can be observed in carving ancient on wood, bone, stone, and pottery that took place with the aim of transferring information or keeping records (Malekifar, 2004). Powering for predicting future shows itself in very early life; in fact, as soon as understanding this vital issue by the baby that his or her crying results in reactions of others. So it must be said that thinking about the future is not a new category. This category is a universal phenomenon that can be traced its roots in pre-human history (Pedram, 2014). Futures studies including the collection of efforts, processes by using resources analysis, models and agents of change or stability, to visualize potential future and to plan for them. Futures studies show how "Today through tomorrow is born from the changes" (or no change) (Bell, 2004). Futures studies are taken from an equivalent of the Latin word "futures studies. The word

To cite this paper: Keshavarzi, M., Yarmohammadian, M., \& Nadi, M. (2019). Teaching Methods based on Futures Studies Development in Iran Higher Education Curriculum. Iranian Evolutionary and Educational Psychology Journal, 1, 2, 69-81. 
"futures" is used because of considering some imagined future rather than just one future that utilized by extent range of methodologies (Fateh Rad \& Jalilvand). In general, the current situation in all areas of the world that changes are done quickly, foresight and organization of scientific activities is necessary to predict the future. In this respect, it can be argued that if the educational system of every country is not based on foresight and doesn't improve it prospective members, then their ability to prevent will not be able to provide a beneficial outcome; Because with the lack of principle, futures studies lose many opportunities to see the achievement supply (Marzooghi, Heidari, \& Heidari, 2014). Freed and McLaughlin (2011) and its cognition should be created for the sake of the students. The above expression means that the students should be able to imagine a better future in their field, issues and possible changes and belief in their ability to respond to changes in the future. In fact, it is expected that students while studying at university, regardless of their field of study, can, in addition, have good conceptual understanding of foresight, become familiar with some methods of futures studies and also have a good spirit while having ability to perform the necessary calculations to predict the future, foresight and the ability to be fostered in student (Masini, 2011). It has been established that futures studies help them to test their imagines from future and by this way, the quality of the decisions that are for the future improved not to be passive in the face of the future and can actively influence the future (Parsa, Keshavarzi, \& Dehghan, 2011). The researches that have been done about the subject of Futures studies are rare in the higher education curriculum. In some of these studies, positive relationship skills and competencies of teachers, quality of learning education environment have been studied (Freed \& McLaughlin, 2011), Quality of Curriculum (Mozaffari, 2010), quality and manner of education to develop the ability of futures studies. Masini (2011); believes that students' power of futures studies growth can be improved through education during the academic years; Thus it can be argued that one of the important variables that can affect students' potential of futures studies growth, is the quality of their learning experiences. Slaughter (2002) states that open-ended teaching and learning strategies face with the traditional discipline of education. Future-oriented curriculum rather than learning facts emphasize the processes of learning how to learn and know the development of skills more important than receiving absolute knowledge about future.

Also, numerous studies have been conducted on factors that affect on teaching-learning process. These factors include the climate and environment of educational effects (Wilson \& Fowler, 2005). The effect of evaluation methods (Leung, Mok, \& Wong, 2008); Assessment of students' learning from skills of studying and learning and their relationship with their academic status (Torkzadeh, Mohammadi, \& Sutoodehfar, 2015) and (Torkzade \& Keshavarzi, 2016); The relationship between learning strategies and motivational orientation in explaining academic achievement (Samadi, 2012); Self-directed in readiness learning and learning styles (Safavi, Shooshtari, Mahmoodi, \& Yarmohammadian, 2010); and the role of Informational Communication Technology(ICT) in evolution of process of learning and teaching (Najafi, 2010). Also, it has been considered as a positive relation of futures studies and academic achievement (Parsa et al., 2011).

Researches in the field of learning and teaching are often focused on the framework; styles; skills and learning strategies and more tend to the past and the present. But in none of the studies in the learning-teaching process; futures studies and foresight have not been studied. Therefore, it is 
necessary to be developed in an approach based on futures studies and a new attitude in the field of learning - teaching in a dynamic educational system. In the researched by the authors, such a vibrant educational system was not found in the field of learning and teaching based on futures studies development in higher education. This research was conducted with the same goal and attempted through investigating experts' theories in the area of curriculum development and futures studies to identify and deliver obstacles, strategies, and consequences of compiling of the teaching methods based on futures studies development in higher education curriculum in Iran.

\section{Information collection method and exploration}

The primary method for information collection in this research is a semi-structured interview. With the recommendation of supervisor, four preliminary interviews were accomplished and then the main interview was started. It has been held after doing the preliminary concordances with persons and regulating the sessions time in the researcher office or the responder's workplace. After the start of a session, for 10 minutes, complete explanations have been presented on the interviewee about the purpose of doing the research and the method of concluding from it, and then the session has been started. For having complete information, meantime taking permission from the interviewee, all sessions have been recorded, and according to these documents, the interview text has been implemented. The method of managing the session has been in this manner that at first with proposing 2-3 general questions, the researcher has entered to the session subject and by making using of responses given by interviewee, the session has been managed, and next questions have been asked. During the sessions, it has been attempted that without creating sensitiveness in interviewee, deviation from the session subject to be prevented and merely movement to be accomplished in the predetermined frame. Check-list questions of researcher have been the base for the cognition of the interview reliability. After asking all pre-determined questions and also the conclusion of unpredicted issues, the interview was ended. In this research, the data obtained from semistructured interviews and information existing in the theoretical sources has been obtained. The information provided from interviews has been coded, and it was used in making the main categories of the research.

At current research, using of semi-structured interviews led to propose of the questions that at first there was no awareness about them. For example, the interviewed professors proposed some cases of their experiences and reminiscences which led to exploring new concepts and categories about the research subject. These issues and categories were used as an important source of information during the research process.

In this research, the interviews have been held individually and the time of each interview has been about 60 minutes (between 50 to 80 minutes) averagely. After the end of interviews and implementation of them, it was attempted that the obtained concepts to be arranged and classified. The purpose of this stage was to identify the concepts and categories in the triple stages of coding with soaking in the data that a phenomenon occurs under what conditions and in what ground. 
Information analysis method: Data collected during the interview process have been obtained and analyzed by open, axial and selective coding process and the qualitative data were analyzed by using of professional software of MAXQDA 12.

Open coding: Open coding is an analytical process that according to it, the concepts are identified expanded according to their features and dimensions. The main analysis method that these activities are done according to it is to propose the question about data, compare the events and other phenomena that according to their similarities and differences with similar events, a common title is given to them and they are placed in one category (Corbin \& Strauss, 2008).

The analysis unit in this research has been the paragraphs, namely, at first the interviews text has been implemented, and after elimination of unrelated sayings to the research subject, the information was classified in the frame of tens paragraphs. Then these paragraphs concerning the issues inserted into them were classified, and the paragraphs which had similar subject were placed beside each other. In other words, all sayings implemented from the interview sessions have been studied one after the other, and the concepts have been pulled out from the heart of the speeches. In the coding procedure, two main techniques of comparing and asking were used in which comparative questions were asked. In this stage, basic questions like what time? Why? Where? How? How much? Have analyzed the data. In this stage, the concepts with scientific value have been pulled out from the text of persons, sayings and one name has been allocated for each one of them. There are three general methods for naming the categories:

1. Self-analyzer luminal structures,

2. Technical terms which come out from theoretical and specialized backgrounds and

3. A language which is applied by informers (Johnson \& Onwuegbuzie, 2004). At current research, mostly a combination of researcher-made codes and also concepts mentioned by interviewees has been used. In this stage of coding, the process of making the concepts was very time-consuming and laborious and led to a large number of concepts.

Axial coding: Axial coding includes the process of connecting the subsidiary categories to more main categories. This act includes a complex process of inductive and deductive thought which is done during several stages. This process like open coding is done through comparing and proposing questions. Of course, in axial coding, using of these methods is more concentrated, and it is attempted that the categories to be created and explored according to the paradigm model (Brannen, 2017). In this stage, a link was established between one category and its subsidiary categories. This work is done by applying a paradigm model including "obstacles", "phenomenon", "context", "strategies" and "consequences". Formation of these relations entitled "paradigm model" on behalf of Strauss and Corbin helps to clarify the relations among phenomena, concepts, and categories.

In this stage of coding, some questions were proposed to specify the kind of relation between the concepts. This was done by placing similar concepts beside each other. This affair caused the concepts that can form more main categories with each other to be recognized and each one can be included in one of these categories. After the division of all concepts in the main categories, the concepts were studied again with this view so that the obstacles, executive strategies and also 
consequences arising from them to be segregated from them. After the end of this stage, paradigm models were drawn.

Selective coding: In this stage, the researcher takes action for modeling and developing the theorems or hypotheses. In selective coding, categories about each other are supplied in the frame of a model and their relationship is described. In this stage, the theory is presented in different forms. In this stage, the theory can be expressed in the form of fictional and anecdotal comments in the form of a diagram or the frame of a set of theorems or hypotheses (Iman, 2012: 82).

After determining the category, according to the paradigm model, the subsidiary categories were connected to the main categories (which had been obtained in the axial coding part). After this stage, the final model has been drawn in which the relation of a cored category with other categories was indicated.

\section{Results}

In open coding, a total of 107 conceptual codes from all comments of interviewees were obtained. The obtained concepts were compared with each other, and the concepts that semantically had proportion with each other and expressed a unit issue became in the form of one category, and a name was considered for them. For naming the categories, if the intended category had an explicit name and known concept in the theoretical sources, that name would be used to prevent it from different inferences of persons at the time of studying the results. Then the concepts which were related to each other were placed beside each other and formed a new set. In axial coding, the concepts of the second level were obtained. With this trend, the number of concepts was reduced remarkably. In the last stage, the main category of the research namely compiling the purposes was identified in selective coding.

For drawing the paradigm model, 107 codes were divided into three parts of obstacles, strategies, and consequences. The number of first and second levels concepts about obstacles was reduced to 15 and 4 codes, and in strategies issue, it was reduced from 75 to 7 codes, and this number in consequences was reduced from 17 to 4 codes. The following figure indicates the research findings in the paradigm model.

In fact, the model of paradigm research that was created from combination and integration, the core category, obstacles, strategies, and consequences has been codified as follows: 


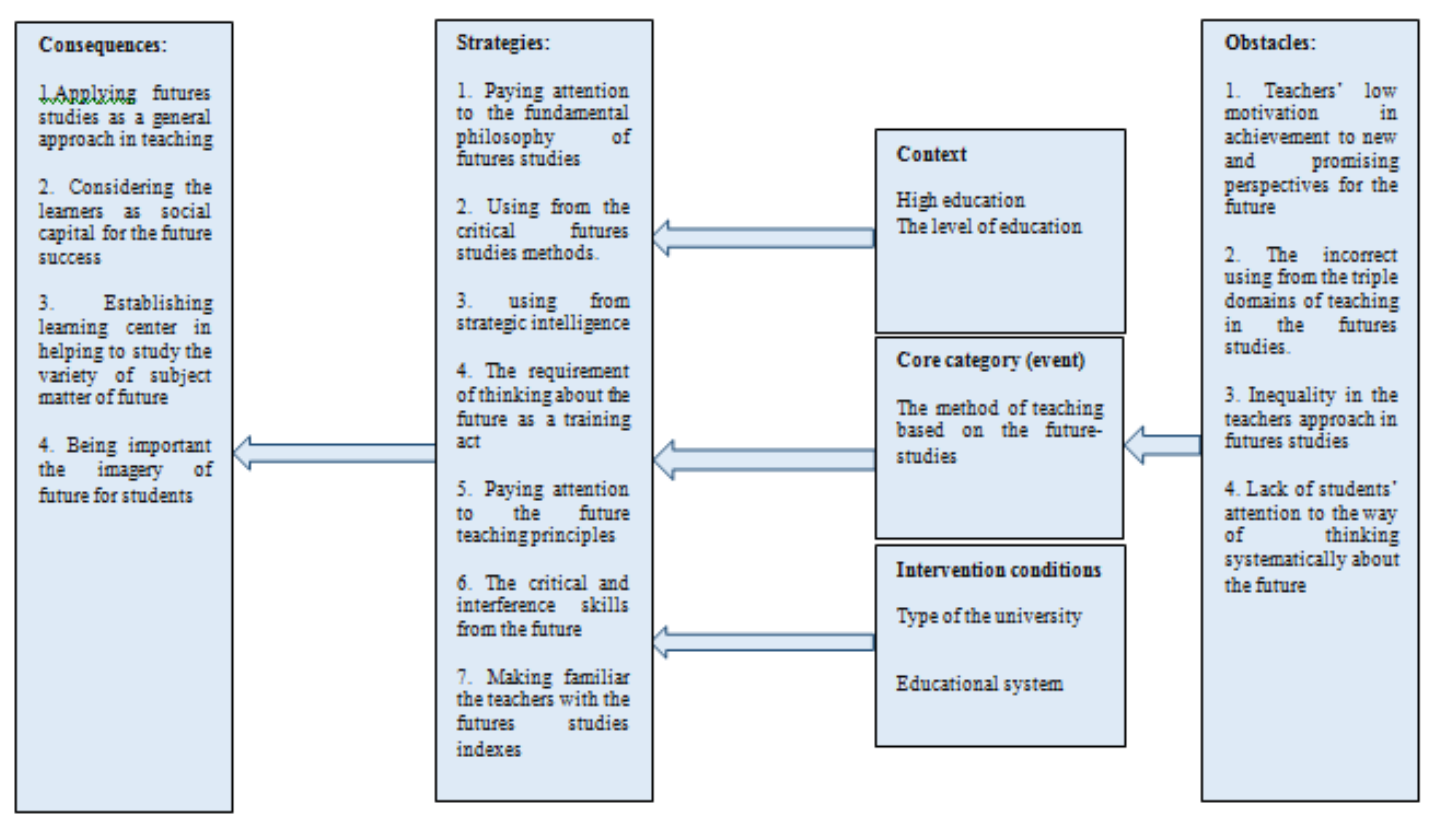

Figure 1: The paradigm model for determination to the teaching methods for the curriculum in order to the futures studies development.

Obstacles: The number of the first level concepts about the obstacles is 15 and on the second level were about 4 codes that included: Teachers low motivation in the achievement to new and promising perspectives for the future. The incorrect using from the triple domains of teaching in the futures studies, inequality in the teachers approach in futures studies, lack of students attention to the way of thinking systematically about the future. In the following, each one of sub-categories has been presented with a sample of interviewees, comments.

Teachers low motivation in achievement to new and promising perspectives for the future Unfortunately the scientific appointment and job promotion of teachers are too much based on the research outputs and aren't according to their skills. So the teachers have the lower motivation for developing their skills and promoting the quality of teaching. This problem when being solved that the quality of teaching, evaluation and the learning outcome turned into the main priority for the institutions (The interviewee, No: 13).

The incorrect using from the triple domains of teaching in the futures studies

We presented one example to you: Bloom said in the evaluation discussion when we want to evaluate the students and children we must evaluate five cognitive domains, including knowledge, comprehension, application, analysis, synthesis, and evaluation. However, at the universities, unfortunately, we have yet stated at the first three-domain of cognitive, and we do not implement the psychomotor and affective domains (interviewee, No: 3).

Inequality in the teachers approach in futures studies: After the first problem or the problem and shortage, we have at the universities in the futures studies, one of the differences between our approaches with others. So we have to equal our approaches and see from what approach we are using (Interviewee, No: 3) 
Lack of students' attention to the way of thinking systematically about the future Unfortunately, in some cases, we will not prepare the thinking of the present-orientation for our students. For example, the student does not know what to study and is searching for one, moreover, what to do after graduation. The above-stated expression is inconsistent with the purpose of higher education in training specialists.(Interviewee, No: 9).

Strategies: The number of the first level concepts about the strategies is 75 and on the second level is 7 codes, which includes: "paying attention to the fundamental philosophy of futures studies, using from the critical futures studies methods, using from strategic intelligence, the requirement of thinking about the future as a training act, paying attention to the future teaching principles, the critical and interference skills from the future, making familiar the teachers with the futures studies indexes", and in the following, each one of sub-categories has been presented with a sample of interviewees, comments.

\section{Paying attention to the fundamental philosophy of futures studies}

In interviewee's view (No: 7), every approach is based on the fundamental philosophy and specific ideology. In fact, the approach cannot be without the philosophy background, because it has specific ontology orientation and epistemology, and axiology. So the futures studies can be an approach that is affected by the original thinking and Postmodernism philosophy and in the ontology, epistemology, and axiology also are affected by this postmodernism philosophy. Although all of the postmodernisms are not optimistic about the futures studies, the advocates of the critical orientations and re-conceptualization accept the future as a reality, and the teachers and experts of education and curriculum are prohibited while paying attention to present time and staying in the past(interviewee, No: 7).

Using from the critical futures studies methods

The methods that are suggested in this context includes group method, projects, and assignment, methods of solving problem, new methods of thinking and techniques of the brainstorm, that can be very effective in this area. Brainstorm, in fact, is to share the ideas, in a group that can create some new ideas and creativity be created and can also be an important subject spark for the future. In fact, the participation methods can be effective in this method and can involve the people's insights and attitudes to the different issues and invite them to critical thinking. The logical thinking can also be effective. It is not possible to accept everything, and we have to think of them (Interviewee, No: 4).

\section{Using from strategic intelligence}

In higher education, we must consider all the values that are possible for a student to access in future. A student has the strategic intelligence in the higher education if he or she has eight kinds of intelligence such as verbal, affection, logical, naturalism, inter-individual, computing, computer and technological and the social skills (interviewee, No: 5).

The requirement of thinking about the future as a training act

In my opinion, establishing the research and foresight studies centers can be more critical in sustainable development attitude, cognition and predicting the future and foresight in facing with the future changing. In our country that is as the developing countries, because of limitation of the scientific forces outside from the universities and the scientific centers, it is a necessity that 
the universities devote a suitable share from their activities to the futures studies. Thinking about the future as a training activity is a necessity (Interviewee, No: 13).

Paying attention to the future teaching principles at the classroom

Traditional methods should be forgotten, and classroom management should be participatory. All individuals (teachers and students) should be responsible for learning from each other. Because of long contexts, emphasis will be on basic principles, and the other slight contents are not effective. In upcoming classrooms, the goals are based on the individual life (present and future). Classes should be ready to use the capacity that provides new technologies. Upcoming classes will focus on meta-cognitive, self-directed and motivation strategies (interviewee, No: 12).

The critical and interference skills from the future: I believe that four key skills for success in the future of higher education graduate include communication skills, computing, and use of information technology and learning how to learn. All institutions of higher education should help students in achieving these goals. (Interviewee, No: 8).

Making familiar the teachers with the futures studies indexes

It should be considered to teachers familiar with foresight indexes and using scenario- writing in improvement courses of faculty members and familiarity with educational soft wares. (Interviewee, No: 5).

Consequences: The number of first level concepts about consequences with 17 codes and in second level with 4 codes includes: applying futures studies as a general approach to teaching, considering the learners as social capital for the future success, establishing learning centre in helping to study the variety of subject matter of future, being important the imagery of future for students. In the following, each one of sub-categories has been presented with a sample of interviewees, comments.

Applying futures studies as a general approach to teaching

Future studies can be considered from two perspectives the first subject is about training individuals of futurist that one curriculum based on futures studies can be written . However, another issue that may be considered is that we can have an approach to teaching and learning. In fact, this approach must pay attention to predict future. (Interviewee, No: 4).

Considering the learners as social capital for the future success

Training competent teachers and students in different fields and investment and expending in training different periods may be appropriate. Students should be considered as a social capital in higher education. Each educational system should be looking to the future for dynamism and eloquence. (Interviewee, No: 6).

Establishing learning centre in helping to study the variety of subject matter of future

Establishing teaching and learning centres in universities can be important resources for faculty members in all colleges. Moreover, help to the colleges in solving problems of the classroom and curricular, and plan for the faculty members and new instructors and help them in designing lessons and evaluations. (Interviewee, No: 13).

Being important the imagery of future for students

I believe that the imagery of future for all students is important. I believe that it is necessary for students to become familiar with these discussions as one of the main elements of the curriculum. (Interviewee, No: 5) 


\section{Discussion}

The method of teaching is directly effective in the futures studies. Making some changes in the teaching method can have a considerable effect on the students' futures studies. Among the elements of the curriculum, methods of teaching have the strongest relationship with the students and the concepts of the futures studies rather than others items.

Tonkaboni and Masumi (2016) state that Changes in teaching methods can have a substantial impact on futures studies of students. All the elements of the curriculum teaching methods have the highest communication with the students and are close to the concept of futures studies more than any other component. Teaching plans should be more oriented towards learning and active teaching. Tonkaboni and Masumi (2016) state active learning is learning that occurs with minimal interference of external factors. In this method of learning, the instructor is at the same level of other factors such as the learning environment and educational resources and only acts as a facilitator of learning. Solati, Javadi, Hosseini Tashnizi, and Asghari (2010) conducted a study on the medical sciences students and found that the more students engage in the teaching process, the more it provides more utility for the students.

Parrish (2016) in his research states: A major agenda of higher education institutions is to equip students to be employable and 'future ready' graduates; achieve their professional and personal goals; and respond, in a socially responsible way, to the challenges of the 21 st Century. These aspirations require quality teaching and learning that is future-oriented and student-focused.

In responding to the first question of our study (What Obstacles are in determination of the higher education teaching methods for developing the futures studies?) The results showed that the teachers' executive engagement, expending no enough time for teaching, not considering importantly the new points of views in teaching, not using from active and participatory learning and the lack of the power for analyzing the future issues all of these are the items that prevent from developing the futures studies in the higher education and the interviews have emphasized on them.

Although there are some shortage fundamentals of epistemological in the futures studies, basically this criticism is considerable that the educational systems will not consider to their mission. It means that preparing students for having needed knowledge and skills for effective participation in the present society and the future (Slaughter, 2002). Mahmoudzadeh and Mahboubfar (2012) in their research entitled: "survey in the field of futures studies in the world and planning of futures studies in higher education Islamic Republic system of Iran "conclusion was that the most important basic challenge in higher education Islamic Republic system of Iran in the field of futures studies, is ignorance and lack of insight of the elites in society about this issue. To find and fill the gap between what is taught in universities and what is needed for graduators, curriculum designers should be aware of trends of governmental resource, the current trends, future of jobs and aims and the available facilities in the society.

In general, "Teachers' low motivation in achievement to new and promising perspectives for the future, The incorrect using from the triple domains of teaching in the futures studies, inequality 
in the teachers approach in futures studies, lack of students' attention to the way of thinking systematically about the future" were the obstacles that the interviewees expressed.

In responding to the second question (What strategies result in futures studies development in compiling the teaching methods of higher education?). According to the interviewees' views, "the teachers and students and the concepts are related to each other. When we discuss the futures studies, the students must be so active, and the teacher should use from the different methods. When it comes to future studies that we want to educate the person we should have a series of attributes such as creativity and critical thinking. Therefore the content that we design must be the one that conducts students to creative skills, critical thinking, and questioning skills, and teacher finds a special place. The teacher cannot be the only element of the classroom rather should be a facilitator for students in learning.

Hicks (2002) in their study to classify targets for future action, as a form of education conducts to such as students' motivation, anticipating change, critical thinking, clearing values, decision making, creative imagination, a better world and responsive citizen. The classroom has a rich feeling environment in which students and teachers experience a wide range of emotions. Emotions are affected by all aspects of learning such as attention, motivation, interest, memory, creativity and social interactions. While negative emotions, in general, prevent learning and experience, positive emotions lead to improved outcomes for teachers and students. Therefore, the ability to regulate emotions is an essential skill for teachers and students for success in the future (Bussey, 2016). If we accept that we need to prepare students for very different future with what we know, in that case, our presumption needs to change about education. This change required to have a correct curriculum which can provide opportunities for individuals to participate in lifelong learning, and at the same time change our attitude about teacher's role as a provider of absolute knowledge in to the innovator, researcher, and participatory with learner during the learning process (Khademi \& Zare, 2013). Curriculum designers can do foresight about all aspects of higher education and curriculum elements. Changing curriculum and its future depend on changes and future of society and new formations of another organization. No doubt with the emergence of new formations in society, curriculums and training will also be new forms.

In general, paying attention to the fundamental philosophy of futures studies, using from the critical futures studies methods, using from strategic intelligence, the requirement of thinking about the future as a training act, paying attention to the future teaching principles, the critical and interference skills from the future, making familiar the teachers with the futures studies indexes, were the strategies that the interviewees expressed.

In responding to the third question (What would be the consequences of designing higher education teaching methods based on futures studies development?) according to the interviewees' speeches "the futures studies is considered as an approach." Inattention to the current society and information explosion, and the needs we are facing with them nowadays, and the different issues that we have, we must consider the futures studies, not as a component, rather as a general approach to teaching". Maroofi and Karami (2015) in their articles stated: Rapid social changes and new technologies will confront humanity with challenges in the future. Preparing people to deal with these challenges is one of the most fundamental goals of education and higher education. Therefore the role of curriculum planners is also determinative. 
Curriculum designers study and explore in teaching with the help of experts of futures studies. This issue is possible from studying the future and futures studies.

In general, "applying futures studies as a general approach to teaching, considering the learners as social capital for the future success, establishing learning center in helping to study the variety of subject matter of future, being important the imagery of future for students and in the following, were the consequences that the interviewees expressed.

In responding to the fourth question, (Is it possible to design a model for compiling of teaching methods based on the futures studies development in the higher education?). The final model of the research that in fact has been created from combination and integration of the main category, obstacles and executive strategies and their consequences has been compiled as follows:

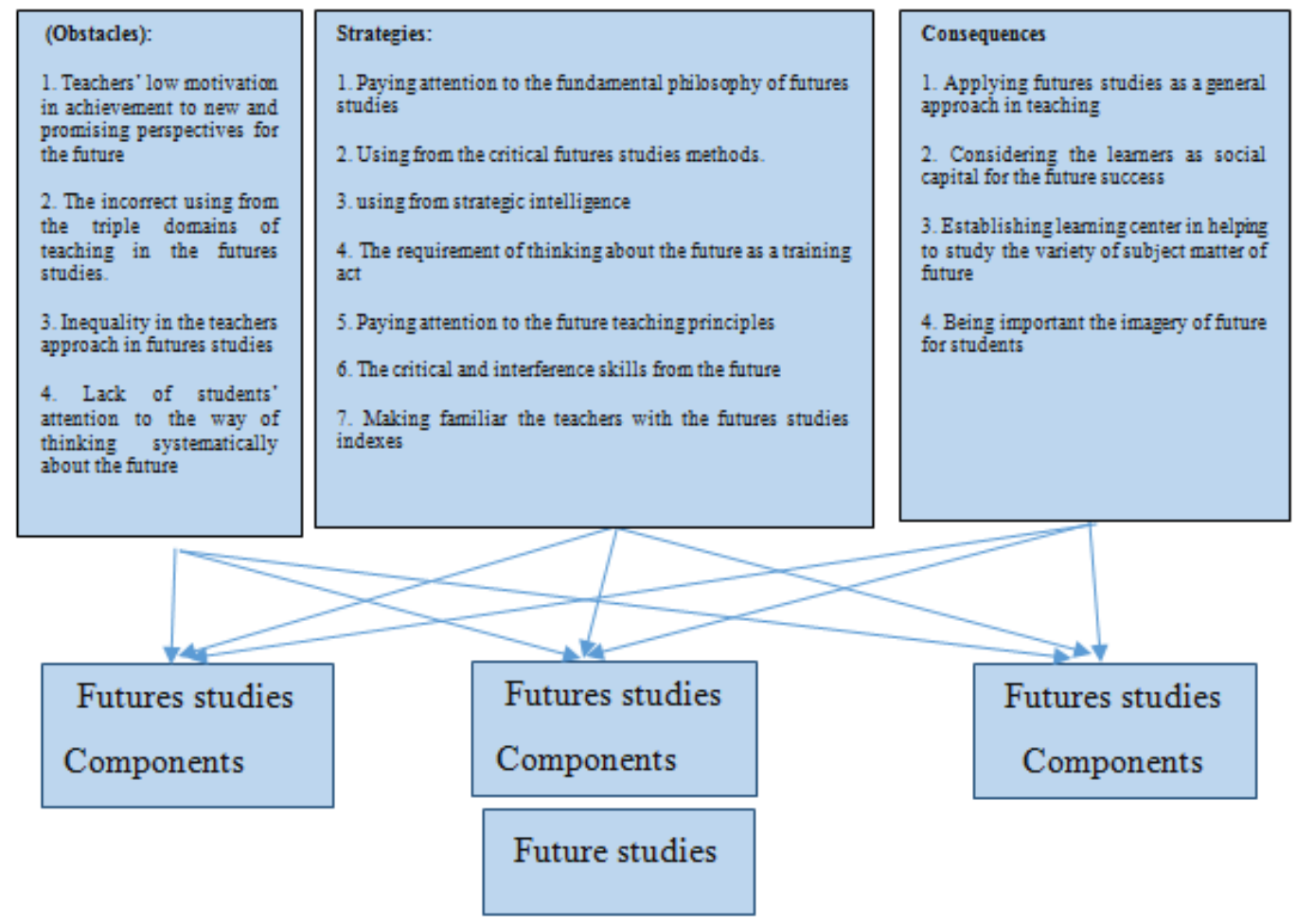

Figure 2: Teaching methods based on futures studies development in Iran higher education curriculum

In attention to the final model, "designing the teaching pattern based on the futures studies development in Iran higher education curriculum" the curriculum designers should consider the futures studies components in higher education teaching. So the need for planning especially in activities of teaching and learning is an undeniable fact to achieve the goals. Futures studies are a systematic discipline to study future probabilities within a certain time frame. The developed curriculum will be used in the education system so that what has been implemented in the education system would have a clear direction in resulting better future generation without loss of unnecessary cost, energy, and resources (Siraj \& Abdullah, 2011). 


\section{References}

Bell, W. (2004). Foundations of futures studies, volume 1: Human science for a new era (Vol. 1): Transaction publishers.

Brannen, J. (2017). Mixing methods: Qualitative and quantitative research: Routledge.

Bussey, M. (2016). The Hidden Curriculum of Futures Studies: Introducing the Futures Senses. World Future Review, 8(1), 39-45.

Corbin, J., \& Strauss, A. (2008). Basics of qualitative research: Techniques and procedures for developing grounded theory. Thousand Oaks.

Fateh Rad, M., \& Jalilvand, M. Introduction to the epistemological foundations and Methods of Future Studies. Journal of Futures Study, 2(8), 27-52.

Freed, P. E., \& McLaughlin, D. E. (2011). Futures thinking: preparing nurses to think for tomorrow. Nursing education perspectives, 32(3), 173-178.

Hicks, D. (2002). Lessons for the future: The missing dimension in education: Psychology Press.

Johnson, R. B., \& Onwuegbuzie, A. J. (2004). Mixed methods research: A research paradigm whose time has come. Educational researcher, 33(7), 14-26.

Khademi, M., \& Zare, R. (2013). 21st-Century Curriculum: Basic Education in Today's Changing World. Tehran: Avaye Noor Publication.

Leung, S. F., Mok, E., \& Wong, D. (2008). The impact of assessment methods on the learning of nursing students. Nurse education today, 28(6), 711-719.

Mahmoudzadeh, A., \& Mahboubfar, M. S. (2012). Surveying the futurism field in the world and futuristic planning in the higher education system of Iran Islamic Republic. Paper presented at the First national conference of futurism, Tehran.

Malekifar, A. (2004). The art and science of discovering the future and shaping the desirable world in future. Tehran: Karaneye Elm.

Maroofi, Y., \& Karami, Z. (2015). Providence and futures study: A approach to curriculum development. International Online Journal of Educational Sciences, 7(3).

Marzooghi, R., Heidari, E., \& Heidari, M. A. (2014). Study of the Relationship between Qualities of

learning Experience and Development of Students' Futures Research Ability. Strides Dev

Med Educ., 11(2), 131-138.

Masini, E. (2011). How to teach futures studies: Some experiences. Journal of Futures Studies, 15(4), 111-120.

Mozaffari, A. (2010). Future studies of cross-border context. Journal of Order and Security Guards, 4(2), 25-47.

Najafi, H. (2010). The Role of ICT in the Development of the Teaching-Learning Process. Peak Nour, 9(1), 51-59.

Parrish, D. R. (2016). Principles and a model for advancing future-oriented and student-focused teaching and learning. Procedia-Social and Behavioral Sciences, 228, 311-315.

Parsa, A., Keshavarzi, F., \& Dehghan, N. (2011). Measure the effectiveness of education and educational success of the future capabilities (Case Study - Shahid Chamran University). Paper presented at the First Iranian International Conference of Management, Futurism, Entrepreneurship, and Industry in Higher Education, Sanandaj, Iran. 
Pedram, A. (2014). Futures Studies in a glance Tehran: Organization of Research and Policy Studies.

Safavi, M., Shooshtari, S., Mahmoodi, M., \& Yarmohammadian, M. H. (2010). Self-directed learning readiness and learning styles among nursing students of Isfahan University of Medical Sciences. Iranian Journal of Medical Education, 10(1), 27-36.

Samadi, M. (2012). Relationship between motivational orientation and learning strategies in predicting academic success. Education Strategies in Medical Sciences, 5(2), 105-111.

Sardar, Z. (2010). The Namesake: Futures; futures studies; futurology; futuristic; foresightWhat's in a name? Futures, 42(3), 177-184.

Siraj, S., \& Abdullah, M. R. T. L. (2011). Development of Future Curriculum via Futures Studies. Online Submission.

Slaughter, R. A. (2002). New thinking for a New Millennium: The knowledge base of futures studies: Routledge.

Solati, M., Javadi, R., Hosseini Tashnizi, S., \& Asghari, N. (2010). Desirability of two participatory methods of teaching, based on students' viewpoint. Hormozgan Medical Sciences Journal, 14(3), 191-197.

Tonkaboni, F., \& Masumi, M. (2016). Development of Teaching Plan in the Curriculum of Medical Sciences. International Journal of Learning, Teaching and Educational Research, 15(7), 65-77.

Torkzade, J., \& Keshavarzi, F. (2016). Relationship between Futurism and Educational Performance of students in Medical Sciences of Shiraz University: Mediation Role of Goal Orientation. Research in Medical Education, 7(4), 3-12.

Torkzadeh, J., Mohammadi, M., \& Sutoodehfar, S. (2015). Developing and Validating of the Teaching-Learning Comprehensive System in Higher Education. Journal of Curriculum Research, 4(2), 93-116.

Wilson, K., \& Fowler, J. (2005). Assessing the impact of learning environments on students' approaches to learning: Comparing conventional and action learning designs. Assessment \& Evaluation in Higher Education, 30(1), 87-101. 